\title{
Mula kay GMA Hanggang kay Duterte: Kritika sa Ilang Dokumentaryong Politikal at Pagmamapa sa Tunguhin ng Dokumentaryo sa Panahong Pinapaslang ang Politikal Choy S. Pangilinan
}

Pangkalahatang layon ng papel na ito na lapatan ng kritika ang ilang dokumentaryong politikal na nilikha ng mga indibidwal at ng mga pampelikulang kolektibo mula sa panahon ng panunungkulan ni Gloria Macapagal Arroyo, Benigno Aquino III hanggang sa kasalukuyang "pasistang" (Imbong, 2020) rehimen ni Rodrigo Roa Duterte.

Sa kabuuan, may tatlong ispesipikong layunin ang papel. Una, pahapyaw na mailatag at mabigyang linaw ang isinusulong na pilosopiya at tindig ideolohikal ng mga dokumentaryong tinaguriang dokumentaryong politikal. Ikalawa, malapatan ng maka-uring kritika at re-eksaminasyon, patikular sa antas ng ideolohikal na panunuri, ang mga sumusunod na dokumentaryo-Red Saga (Dalena, 2004), Sa Ngalan ng Tubo (Tudla Multimedia Network \& EILER, 2005), Tundong Magiliw (Maranan, 2011), The Guerilla is a Poet (Dalena,K.\&Dalena,S., 2013) at Yield (Tagaro \& Uryu, 2017). Panghuli, layon din ng papel na makapag mapa ng ilang proposisyon kung sa papaanong paraan lubos na mahihigit ang radikal na potensyal ng mga dokumentaryong politikal lalo na ngayong kay ilap ng hustisya at katwiran samantalang kay igting ng ligalig, kawalang pananagutan, at pasismo.

The comprehensive objective of this paper is to critique and interrogate selected political documentaries created by individuals and film collectives from the time of incumbency of Gloria Macapagal-Arroyo, Benigno Aquino III, until the current "fascist" (Imbong, 2020) regime of Rodrigo Roa Duterte.

In whole, the paper has three specific objectives. First, subtlety lay and give clarity to the impelling philosophy and political stance of documentaries deemed political in nature. Second, apply a classbased critique and re-examination, particularly on the level of an ideological analysis, to the following documentaries_Red Saga (Dalena, 2004), Sa Ngalan ng Tubo (Tudla Multimedia Network \& EILER, 2005), Tundong Magiliw (Maranan, 2011), The Guerilla is a Poet (Dalena,K.\&Dalena,S., 2013) and Yield (Tagaro \& Uryu, 2017). Lastly, another goal of the paper is to be able to map out some propositions on how to fully extract the radical potential of political documentaries especially at this time of elusive justice and reason, while unrest, impunity, and fascism are intense

Keywords: political documentary documentary, film criticism, state fascism, nation state 
Pangkalahatang layon ng papel na ito na lapatan ng kritika ang ilang dokumentaryong politikal na nilikha ng mga indibidwal at ng mga pampelikulang kolektibo mula sa panahon ng panunungkulan ni Gloria Macapagal Arroyo, Benigno Aquino III hanggang sa kasalukuyang "pasistang" (Imbong, 2020) rehimen ni Rodrigo Roa Duterte. Sisiyasatin sa pag-aaral ang tindig politikal ng mga dokumentaryo nang sa gayon ay mailantad ang tunay na ideolohikal na kiling nito partikular sa interogasyon nito sa ugat ng tunggalian ng mga uri, kahirapan, paghihimagsik, digmang bayan, at pagsasabansa halimbawa. Kaakibat nito, nais ko ding kilatesin sa aking pag-aaral kung saang diskursibong posisyon tayo inilulugar-bilang mga manonood at mamamayan-ng naturang mga dokumentaryo.

Sa kabuuan, may tatlong ispesipikong layunin ang papel. Una, pahapyaw na mailatag at mabigyang linaw ang isinusulong na pilosopiya at ideolohiya ng mga dokumentaryong tinaguriang dokumentaryong politikal. Ikalawa, malapatan ng maka-uring kritika at re-eksaminasyon, patikular sa antas ng ideolohikal na panunuri, ang mga sumusunod na dokumentaryo-Red Saga (Dalena, 2004), Sa Ngalan ng Tubo (Tudla Multimedia Network \& EILER, 2005), Tundong Magiliw (Maranan, 2011), The Guerilla is a Poet (Dalena, K. \& Dalena,S., 2013) at Yield (Tagaro \& Uryu, 2017). Panghuli, layon din ng papel na makapag mapa ng ilang proposisyon kung sa papaanong paraan lubos na mahihigit ang radikal na potensyal ng mga dokumentaryong politikal lalo na ngayong kay ilap ng hustisya at katwiran samantalang kay igting ng ligalig, kawalang pananagutan, pasismo, at pagpaslang sa politikal.

\section{Dokumentaryong Politikal:}

\section{Sining ng Pakikitungali at Daluyan ng Politisasyon}

Ang salitang ugat ng terminong dokumentaryo ay dokumento. Kung pagbabasehan ang modernong gamit sa salitang dokumento, makikitang ang kahulugan nito ay "something written, inscribed, etc. which furnishes evidence or information" (Winston, 1995, p. 11). Ang katangiang makapagsalansan ng mga dokumento upang magsilbing serye ng mga ebidensiya ang taglay na kapangyarihan ng anyong dokumentaryo. Dagdag nga ni Winston (1995), "the evidential status was passed to the cinematoraph and is the source of the ideological power of documentary film" (p. 11). Kung gayon, sa pagsasaayos ng mga aural at biswal na elemento ng isang dokumentaryo, nailalatag nito ang mga ebidensyang kinakailangan upang akayin ang mga manonood sa isinusulong nitong sistema ng pag-unawa, konsepsyon ng realidad, at ideolohikal na posisyon.

At heto ang bentahe ng anyo ng dokumentaryo, may kakanyahan itong makumbinsi at maipaloob sa kanyang taya sa katotohanan ang manonood. Kung kaya't sa totoo lamang, walang dokumentaryong maituturing 
na neutral ang posisyon sapagkat paratihan itong may pinapanigan at sineselyohang pananaw panlipunan. Paratihan itong may kinikilingan. Paratihang may nais pagdalhang sintesis ang areglo ng mga inilalatag na ebidensya na kung susumahin ay ang diskursibong areglo at pananaw pang mundo na nais bigyang diin ng textong pang media.

Kaugnay ng puntong ito, nais kong sumangguni kay Paula Rabinowitz (1994), aniya "[d]ocuments may appear to be neutral sources of historical truth, but documentaries have and present values; they are persuasive, not simply artifactual" (p. 7). Sa madaling sabi, mahihinuhang ang lahat ng dokumentaryo ay anyo ng paghimok sa manonood upang umayon sa lohika at pahalagahang pinapaboran nito.

Komersyal man o alternatibo, marapat mabatid na palagiang may sinasandigang ideolohikal at politikal na interes ang anomang uri ng dokumentaryo. Kailangan, kung gayon, na masalat kung saang antas at uri ka ng pag-unawa inaakay ng textong tinutunghayan. Kailangang maibuyangyang kung kanino at saang interes pumapanig ang bitbit na diksurso ng isang texto upang sa gayon ay mabatid ang lugar nito sa nagaganap na talaban ng pakahulugan, panlipunang mga tunggalian, at antagonismong pang-uri sa isang lipunan halimbawa.

Sa kaso ng tinaguriang dokumentaryong politikal, ibinabalik sa antas ng "politikal" ang pagpapaunawa sa mga bagay-bagay. Ibig sabihin, imbis na maging papakitid ang lapit, ang orientasyon ng dokumentaryong politikal ay ang maipakita at mailinaw ang dialektikal na ugnayan ng mga maliliit na bagay sa tunay na pinag-uugatan nitong mga puwersa at makinisasyon mula sa loob at labas ng lipunan. Tumataliwas ang mga dokumentaryong politikal sa isinusulong na "neutralidad" at idea ng pseudo "obhetibidad" ng mediang komersyal.

Pangunahing interes ng mga dokumentaryong politikal na makapagsulong ng isang makalipunang adhika na may layong gawing aktibo ang mga manonood nito upang maging kaisa sa pagbibigay lunas sa mga krisis panlipunang natutunghayan sa loob ng iskrin. Ito'y sa kadahilanang ang siyang napapanood ay ang siya din namang aktuwal na nararanasan ng manonood at mamamayan sa kanya mismong iniinugang lipunan. Kaugnay nito, nais kong ilatag ang elaborasyon ni Rabinowitz (1994) hinggil sa dokumentaryong politikal. Aniya;

Documentary forms often claim to occupy the neutral position of the document. However the rhetoric of political documentary-from the reportage of the 1930s to the feminist counter cinema of the 1980s-foregrounds sexual, class, racial, and gender differences within its address. 
These differences construct a spectator whose position is located within history, essentially remaking the relationship of truth to ideology by insisting on advocacy rather than objectivity. (p. 7)

Inilulugar ng mga dokumentaryong politikal ang mga manonood nito sa isang posisyon na humihikayat sa kanila na maging mga aktibong ahente sa pagsusulat ng kasaysayan at sa pagkalag sa mga nananaig na tunggalian ng kapangyarihan sa isang lipunan. Iginigiya ng naturang anyo ng dokumentaryo ang manonood at maging ang mga tauhang pinapanood sa dokumentaryo bilang mga panlipunang puwersa na marapat na magkaisa at magsanib upang tuluyang mabago ang konstelasyon ng mga relasyon sa isang lipunan. Pinopolitisa nito ang manonood hinggil sa isang usaping panlipunan upang kalaunan, makaraan mabatid ang ugat ng mga bagaybagay, ay maging bahagi ng aktuwal na hanay na lalahok upang tuluyang magupo at mabago ang sistemang ugat ng naturang mga panlipunang kontradiskyon.

Sa dokumentaryong poltikal, hindi makakasapat ang pagpapakita lamang sa nagaganap. Sa halip kinakailangang itaas ang antas ng pag-unawa ng manonood at mamamayan upang mabatid nila na sila mismo ang prente na maaaring pagmulan ng radikal na opensiba at praksiyolohiya. Ayon nga kay O'Shaughnessy (2007);
A radical cinema cannot simply seek to represent contemporary reality, to be 'realist', no matter how dark the tone it employs. It must bring disagreement over the order of things to the surface, defining the dominated not by their subordination but by their capacity to challenge it while pushing its audience back towards a politics.(p. 4)

Imbis na ipatanggap ang namamayaning kaayusan, ipinapakilala ng mga dokumentayong politikal sa manonood ang kapasidad nilang makita na kakatwa at hindi makatao ang realidad sa isang banda. At upang matanto nila na hindi imposibleng banggain at baguhin ang mga puwersang naglelehitimisa sa mapang-aping sistemang gumigiyagis sa nakararami sa ikalawang malas.

Upang higit pang mapalalim ang ating diskusyon, nais ko muling sipiin sa kabuuan ang isa pang obserbasyon ni Rabinowitz (1994) hinggil sa katangian ng mga dokumentaryong politikal. Dagdag niya;

Clearly, political documentary has seen its mission to point out 'problems' within the social fabric of a nation with the aim of changing them; sometimes the work of documentary 
has been to gather support for a particular 'solution' to a crisis, but increasingly political documentaries serve another representative function-that of self-definition. Radical reportage and documentary films often provide the Left, or its various subcultures, with a self-understanding. It represents itself to itself_-an act of identity-as it represents its positions to a wider community-an act of recruitment. Moreover, radical documentary constructs objects of radical desire; it depicts the subject and object of revolution to itself and through itself, producing an identity that both includes yet differs from its audience. (p. 12)

Tama ang obserbasyon ni Rabinowitz (1994) ng kanyang banggitin na ang unang awdyens ng mga dokumentaryong politikal ay ang organisado ng hanay ng mga nasa kilusan para sa pagbabago. Ngunit hindi ito nalilimita doon. Dahil ang pangkalahatang layon ay upang mahikayat ang kalakhan ng mga manonood nito-na matagal ng binaog at nililinlang ng mga kasapakat ng estado at kapital-upang mabatid ang mga suring mas may katwiran, makatao, maka-uri, at nakabatay sa batayang realidad ng lipunan. Kung ang dominanteng media ay umaayuda sa nangyayaring sistema, lumilikha ng mga pasibong manonood, at pinapakitid ang mga konkretong usaping panlipunan; ang mga dokumentaryong politikal naman may tungkuling magbilad at dumestrungka sa ganoong mga taktika ng pakatotohanan at panlalansi.

Marapat na maging partisano sa tunay na kalagayan ng mga naisantabi ang tinig na bitbit ng mga dokumentaryong politikal. Bukod doon, marapat na may malinaw itong kiling sa hangaring maipakita ang mga tunay na salik ng samu't saring krisis at suliraning panlipunan na ating nararanasan. Ibig sabihin, nais nitong himayin ang mga panlipunang usapin bilang sistemikong resulta ng mga antagonismong pang-uri na nananaig sa isang komunidad, sa lipunan, at maging sa global na espera. Ang mga suring ito ang maaaring paghanguan ng mga alternatibong bista at praxis ng manonood upang higit pang maunawaan ng may lalim ang mga nagaganap sa kanyang kaligiran.

Liban sa mga pormulasyon ni Rabinowitz (1994), mahalaga ding mailapat ang kontexto ng dokumentaryong politikal mula sa hinawang teoretikal na padulog nina Fernando Solanas at Octavio Gettino (1976) sa kanilang seminal na sanaysay na Towards a Third Cinema. Para sa dalawang kritiko, ang larangan ng kultura at kultural na produksyon ang pangunahing daluyan ng mga kaisipang nagbibiay tibay sa patuloy na pamamayapag ng neokolonyalismo, kapitalismo, at imperyalismo bilang mga sistema ng pag- 
unawa at ekonomikong polisiya na patuloy na bumibihag sa mga bansang neokolonya pa din ng Estados Unidos (Solanas at Gettino, 1976).

Ayon kina Solanas at Gettino (1976), sa lunan ng kultura at mga aparatong ideolohikal pinanunuot ng estado at ng mga dibuhista ng kapitalismo ang kanilang mga burgis, konsumerista, anti-mamamayan, at maka-imperialistang mga perspektiba. Sagka kung gayon ang dominanteng anyo ng media at pelikula upang lubos na mahinuha ng mamamayan ang basehang kondisyon ng lipunan sa ilalim ng isang sistemang maka-uri, mapang-api, at mala-kolonyal. Ganoon pa man, sa larangan din naman ng produksyong pang kultura sa pangkalahatan at sa produksyon ng tinaguriang Ikatlong Sine (Third Cinema) sa partikular nakikita nila Solanas at Gettino (1976) ang siwang at oportunidad upang makalikha ng mas militante, makamasa, mapagpalaya, subersibo, dekolonisado, at rebolusyonaryong anyo ng produksyong pang sining at pangkultura.

Bukod sa pangangailangang lumihis sa dominanteng moda ng produksyon at estetika, pangunahing layon din ng Ikatlong Sine, na makapagtaguyod ng isang uri ng sine na muling naglalarawan sa basehang materyal na kondisyon ng mamamayan. Isa sa sinasandigang pilosopiya ng Ikatlong Sine ay ang pagbubukas ng mga bagong posibilidad ng pag-unawa na magsisilbing tungtungan tungo sa patuloy na pagbubuo ng landas tungo sa ganap na emansipasyon ng masa mula sa tanikala ng namamayaning sistema.

Sa kahabaan ng kanilang sanaysay, may isang partikular na talata kung saan tinalakay nila ang maaaring gampanan ng dokumentaryo sa iniimbisyon nilang politikal na proyekto ng dekolonisasyon at panlipunang rebolusyon. Anila;

The cinema known as documentary, with all the vastness that the concept has today, from educational films to the reconstruction of a fact or a historical event, is perhaps the main basis of revolutionary filmmaking. Every image that documents, bears witness to, refutes or deepens the truth of a situation is something more than a film image or purely artistic fact; it becomes something which the System finds indigestible. (Solanas at Gettino, 1976, p. 55)

Batay rito, mahihinuha kung gayon na marapat na magsilbing kontraryo sa lohika ng sistema-estado, naghaharing uri, at kapitalismoang inilalatag na diskurso at perspektiba ng isang politikal na dokumentaryo. Kinakilangang salungatin ng isang obrang politikal ang mga iminuhong disenyo ng nangyayaring kaayusan. Kung gayon, upang masabing tumatalima sa perspektiba ng Ikatlong Sine ang likha-pelikula, 
agitprop, o dokumetaryo man-kinakailngan itong maging oposisyunal sa namamayani at reaksyunaryong politika ng mga naghahari-harian sa lipunan. Oposisyunal sa proseso ng pagkakagawa, distribusyon, at mas lalo na sa ideolohikal nitong adyenda (Solanas at Gettino, 1976). Ito'y sa kadahilanang hindi limitado sa mga experimentasyon sa estetika at proseso ang paglikha ang produksyon ng sining, ngunit isang pamamaraan din ito upang makitunggali at mairehistro ang tinig ng protesta sa mismong sistemang pinagmumulan ng naturang mga ideolohikal,ekonomiko, at politikal na polisyang anti-mamamayan.

Kaugnay nito, kailangan nating matalos na ang mga dokumetaryong politikal ay nakapaloob din sa mas malawak na kategorya ng sining ng protesta. Para kay Alice Guillermo (2001), "[p]rotest art may react not only against a particular regime but against the political/economic system which institutionalizes such inequitable, unjust, and inhuman conditions; thus, it may go beyond protest to proffering revolutionary alternatives" (p. 4). May potensyal kung gayon ang mga dokumentaryong politikal hindi lang upang magsilbing lente sa pagbubuyangyang ng mga tagong iskema kaugnay ng isang usaping panlipunan ngunit may angking kapangyarihan din ito upang magsulong ng mas mataas na panlipunang panawagan. Isang panawagang naka-angkla sa palalatag ng rebolusyonaryong alternatibo bilang susi upang tuluyang mabago ang lipunan.

Bukod sa pagiging daluyan ng katotohanan, pakikitunggali, at sandata sa adhikang makapagmulat, makapag-udyok, at maging kaagapay sa pagpapakilos sa mamamayan, marapat na tangan din ng isang dokumentaryong politikal ang isang maka-uri,makamasa, siyentipiko, at makabayang perspektiba kaugnay ng nililirip nitong relasyon sa pagitan ng paglikha, sining, manonood, at lipunan. Ibig sabihin, marapat na ang bayan ang pinaglilingkuran ng likhang sining. Maging ito man ay pelikula, panitikan, o dokumentaryo halimbawa.

Sa kontexto ng Filipinas, unang nabanggit ang konsepto ng "sineng bayan” sa artikulo ni Roy Iglesias (1984) sa Sunday Malaya noong 1984. Tinalakay sa naturang artikulo ang mga dokumentaryong politikal at biswal na likha ng Asia Visions. Ang mga sinematikong interbensyon ng Asia Visions ay nagsilbing panulukang bato sa pag-usbong ng mga produksyong pang media na may layong maisiwalat ang tunay na kalagayan ng bansa sa ilalim ng pangil ng pasismo at Batas Militar (Bato, 2019; Iglesias, 1984; Roque, 2018). Naging kultural na sandata ang mga biswal na interbensyong ito upang patuloy na maisulong ang adhikang mapalaya ang bansa mula sa diktadurang kumukubabaw sa lipunang Filipino.

Ilan sa mga salalayang layon ng Asia Visions sa kanilang mga likha ay ang makatotohanang pagpapakita sa kalagayan ng lipunang Pilipino at 
dagdag dito'y ang "dokumentasyon ng mga karanasan ng mamamayan" (Roque, 2018, p. 75). Nais din nilang idiin sa kanilang mga likha na may angking kakanyahan ang taong bayan upang mabago mismo ang sistemang gumagapi sa kanila sa kabila ng mga banta ng paninikil at panunupil. Hindi lamang alternatibong uri ng dokumentaryo ang hatid ng mga politikal na pampelikulang kolektibo tulad ng Asia Visions, ngunit hatid din nito ang isang alternatibo, kontradiskursibo, at maka-uring sipat sa lipunan at kasaysayan.

Nagsilbing prekurso ang hinawang landas ng Asia Visions upang patuloy na lumago ang mga pampelikulang kolektibo sa bansa. Ilan sa mga politikal na kolektibong sumunod sa tradisyong hinawan ng Asia Visions ay ang Kodao Poductions (2001), ST Exposure (2002), Tudla Poductions (2003), Sine Patriyotiko (2004), at Mayday Multi Media (2004) (Bato, 2019). Ngunit mahalagang mailinaw na hindi lamang din nalilimita sa mga politikal na pampelikulang kolektibo ang pagsuong sa larangan ng dokumentaryong politikal bilang sandatang kultural at daluyan ng makamasang anyo ng likhang sining. May mangilan ngilan ding indibidwal na manlilikha na ginagamit ang larangan ng dokumentaryo upang makiisa sa pagsusulong ng interes ng sambayanang Pilipino.

Sa pagsusuma, ang mga teoretikal na pagdulog at elaborasyon na inilatag ko sa bahaging ito ng papel ang magsisilbing giya ko sa aking mga pag kilates at panunuri sa ilang textong biswal na aking napiling pag-aralan. Ang mga dokumentaryong lalapatan ko ng pagsusuri sa kahabaan ng pagaaral ay mula sa mga politikal na kolektibong pampelikula at ilang mga indibidwal na manlilikha na may layong gamitin ang larangan ng pelikula upang talakayin ang mga konkretong problemang panlipunan ng bansa.

Ibinatay ko ang pagpili sa mga dokumentaryong lalapatan ng kritika batay na din sa mga nauna ng sipat ng ilang iskolar hinggil sa kanilang pagbasa at klasipikasyon sa mga naturang dokumentaryo bilang sulong at politikal (Arumpac, 2019; Tolentino, 2016). Pinili ko din ang ibang dokumentaryo dahil na din sa pagkilala ng ilang mga gawad parangal na tinitimbang ang mga ito bilang akdang kontradiskursibo sa meta naratibo ng estado.

Nais kong suriin ang naturang mga dokumentaryo upang maibilad ang sinusulong nitong politika sa isang banda at upang malalimang makilates kung ang taya nga ba sa katotohanan ng mga ito ay tunay na nagmumula sa masa, para sa masa, at may malinaw na kritika sa nananaig ng talaban ng uri sa lipunan sa pagitan ng mga iniisantabi at naghahari, ng may kaya at wala, at ng laylayan at ng pambansa-estado. 


\section{"I am Sorry":}

\section{Rehimeng Arroyo at ang mga Dokyung Nakikitunggali sa Estadong Walang Puso}

Sa loob ng panunungkulan ni Gloria Macapagal Arroyo (GMA) mula 20012010, hindi maikakailang ang naging tunguhin ng kanyang pamamalakad sa bansa ay nakaangkla sa pagkitil sa larangan ng 'politikal' (Raymundo, 2006). Makikita ito sa malawakang implementasyon ng Oplan Bantay Laya upang supilin, lipulin at wakasan ang mga tinaguriang kalaban ng pambansaestado.

Sa unang hati pa lamang ng kanyang termino, taong 2006, umabot na sa halos 709 ang biktima ng extrajudicial killings, idagdag mo pa ang 180 katao na sapilitang dinukot, winala at pinatay (San Juan, 2006). Ang kampanya kontra insurhensiya, na panandang bato ng rehimeng Arroyo, ay maiuugat sa hegemonikong istratehiya ng Estados Unidos upang sarhan ang anomang uri ng pagtutol at pagtuligsa sa kanilang adyendang pang militar, ekonomiko, at pampulitika batay na din sa masidhing global na propaganda nila upang isulong ang kampanya laban sa terorismo (San Juan, 2006). Isang kampanyang ang tinutugis ay ang mga nagsusulong ng mas makatao at makamamayang adyendang panlipunan. Ito'y sapakat terorista ang turing at bansag sa sinomang umuusig sa fundamentalismo at idea ng neoliberal na globalismo ng imperyo.

Sa panahon din ni GMA umigting ng lubusan ang migrasyon ng mga Filipino bilang mga overseas contract workers (OCW) dahil na din sa kawalan ng marangal na trabaho sa bansa at kaakibat nito'y ang pagdausdos ng healthcare system sa bansa, brutalisasyon sa kalagayan ng mga mangggaawa, manggagawang bukid, kababaihan, katutubo, at kabataan (San Juan, 2006). Ang ugat ng hindi makataong kalagayang ito ay ang tila may tapa ohong pagsandig ng pambansa-estado sa ethos ng adyendang neoliberal. Isang sistematiko at sistemikong adyendang pang ekonomiya, pampolitika, at pang kultura na pumapabor sa interes ng naghaharing-uri, ng negosyo, at sa mga arkitekto ng liberalisasyon, pribatisasyon at malayang ekonomiya.

Ang pagtalima sa adyendang neoliberal ang salarin sa masidhing paglawakng agwat sa pagitan ng wala at may kaya, sa pagitan ng manggagawa at mga may ari ng negosyo, sa pagitan ng magsasaka at panginoong may lupa, at sa pagitan ng mga nilalapastangan at mga dibuhista ng pasismo at kultura ng kawalang pananagutan. Ika nga ni Mohan J. Dutta (2011) hinggil sa ugnayan ng neoliberalismo at marhinilisasyon;

The markers of marginalization vary widely, including categories such as class, caste, race, gender, nationality of 
origin, sexual, although almost all forms of marginalization carry an economic logic with them with the emphasis on the lack of access to basic resources. The question of the margins has become of increasing interest to contemporary scholars as globalization processes have participated in creating these margins and sustaining them, often operating on the basis of violence to delegitimize the rights of the communities at the margins. (p. 2)

Walang ibinandera ang rehimeng Arroyo kungdi ang pagpapakat ng lahat ng mga pambansang polisiya nito sa dibuho ng neoliberalismo. Pinairal nito ang isang mentalidad ng pamamahala na nagbibigay pabor lamang sa mga polisiyang umaayuda sa kahingian at pangangailangan ng mapang-aping uri at kapitalismo. Dahil sa ganitong tindig ng pambansaestado, naging paatras ang byahe ng bansa tungo sa ganap na pambansang kaunlaran at ang kalakhan ng masa ay patuloy na lamang nasadlak sa kumunoy ng kahirapan.

Kaakibat nito, lantaran ding makikita na hindi nilubayan ng represibong mga aparato at puwersa ng estado ang hanay ng mga nasa kilusang mapagpalaya (Manzanilla, 2006). Tandaan din nating sa panahon ni Arroyo naganap ang karumal dumal na Hacienda Luisita Massacre (Olea at Castaneda, 2004); ang trahedya ng Wowowee na indikasyon ng labis na kahirapan sa bansa (Pangilinan, 2012; Raymundo, 2015); at ang muling pagpasok ng mga sundalong Amerikano sa ngalan ng Balikatan exercises (San Juan, 2006).

Sa ganitong historikal at panlipunang kontexto ko nais sipatin kung sa paanong paraan tumutugon at bumabangga sa namamayaning sistema ang dalawang obra na napili kong talakayin sa papel na ito. Una na nga dito ang poetikong experimentasyon ni Kiri Dalena sa Red Saga (2004) at ang akdang Sa Ngalan ng Tubo (2005) mula sa pampelikulang kolektibo na Tudla.

\section{Red Saga at ang Abstraksyon sa Digmang Bayan}

Isa si Bill Nichols (2001) sa mga nagsabing sa kontemporaryong panahon ng produksyon ng mga dokumentaryo ay tila lumalabo na ang demarkasyon sa pagitan ng tradisyunal na uri ng dokumentaryo at pakikipagsalimbayan nito sa fiksyon. Sa klasipikasyon ni Nichols (2001), ito ang tinatawag niyang poetikong dokumentaryo. Ayon sa kanya;

[p]oetic documentary shares a common terrain with the modernist avant-garde... The poetic mode is particularly adept at opening up the possibility of alternative forms of knowledge to the straightforward transfer of information, 
the prosecution of a particular argument or point of view, or the presentation of reasoned propositions about problems in need of solution. This mode stresses mood, tone, and affect much more than displays of knowledge or acts of persuasion. (pp. 102-103)

Sa ganitong kategorisasyon maaaring maklasipika ang istilong pangestetika ng akdang Red Saga. Sa loob ng texto, pinagsasama at pinagdadaop sa paraang non-linear ang mga imahe ng tunay na kilos protesta, pagmartsa ng Bagaong Hukbong Bayan (BHB) sa kanayunan, ang reenactment ng pang-aabuso ng mga militar sa mga manggagawang bukid, ang poetikong interjeksyon ng pagwawagayway ng bandila mula puti hanggang pula, at ang imahe ng mga duguang kamay. Pinagsasalimbayan at pinagsasanib ni Dalena sa loob ng texto ang siyang "tunay" (rally, BHB, karahasan, tunay na kamay ng biktima) at ang simbolikal(bandila, sayaw, kamay) upang mailahad, sa masining at poetikong paraan, ang dialektikal na ungayan ng kalagayan ng mga manggagawang bukid, hasik ng militarisasyon, at ang matagalan ng digmang bayan sa kanayunan.

Sentral na metapora din ng Red Saga ang utilisasyon sa bandilana pinaiigting ng inilapat na musika at orkestradong kilos at sayaw ng nagwawagayway-upang ipakita ang transpormasyon ng hanay ng manggagawang bukid mula sa pagiging mga tahimik na magsasaka hanggang sa politisasyon nila bilang kaanib ng armadong puwersa ng Bagong Hukbong Bayan. Ang transpormasyon ng kulay ng bandila mula puti hanggang pula ang isa sa mga poetikong kasangkapan ng texto upang ilahad ang naganap na pagbabago sa komunidad sa isang banda at sa kamalayan ng mga tauhan sa ikalawang malas. Nagsisilbing loop ang pagwawagaway ng bandila at pagpapalit nito ng kulay upang kronolohikal na maipakita ang mapait na danas ng mga manggagawang bukid sa ilalim ng isang lipunang militarisado tungo sa paghawak ng armas upang aktibong mabago ang hindi makatarunang kalagayang panlipunan na kinapapalooban ng mga tauhan sa loob ng texto.

Hindi maikakailang malay at may malinaw na intensyon ang may likha na maipakita na hindi lamang sa loob ng biswal na texto nagaganap ang naturang tunggaliang panlipunan ngunit maging sa labas ng filmikong mundo. Sa pagsasalit at juxtaposisyon ng mga imahe ng tunay at poetiko, layong isiwalat ng texto ang ugnayan ng simbolikal at konkreto, ng pelikulang nakikidigma at digmang bayan na nagaganap sa labas ng pelikula, at ng salimbayan ng pelikula, protesta sa kalunsuran, at armadong pakikibaka bilang manipestasyon ng pakikitunggali laban sa mga nasa poder ng kapangyarihan. 
Tama naman ang historyador na si Nick DeOcampo ng sabihin niyang ang pelikula ay "politikal" (Espada, 2004). Ngunit marapat din namang kilatesin ang talas o purol ng politikang taglay nito. Sa katunayan, sa unang malas ay maaaring masabing sulong at mapangahas ang akda, lalo na sa panahong matindi ang kampanya laban sa insurhensiya, ngunit sa ikalawang tingin ay marami din itong hindi naipakita at hindi lubusang natalakay at naisiwalat. At ang mga puwang na ito, kung nabiyan lamang ng dagdag na pansin, ay lubos pa sanang magpapalalim sa diskursong hatid ng texto.

Bagamat biswal na tinutukoy ng pelikula ang armadong pakikibaka bilang solusyon sa mga nagaganap sa lipunan, hindi nailinaw ng akda kung ano nga ba ang puno't dulo ng pangmatagalan ng digmang bayan na nagaganap sa kanayunan at bansa. Batay sa pagkakasalansan ng mga imahe, sadyang pang-aabuso lamang ng militar-na kasangkapan lamang din naman ng estado at ng mga panginoong lupa-ang suliraning kinakaharap ng mga manggagawang bukid sa kanayunan. Ang hindi nahagip ng experimentasyon ni Dalena ay ang mismong pinag-uugatan ng naturang tunggaliang pang-uri na kinapapalooban ng sektor ng mga manggagawang bukid at ng Bagong Hukbong Bayan bilang armadong prente at puwersa ng Partido Komunista ng Pilipinas at Kilusang Pambansa Demokratiko.

Hindi malinaw na naitagni ng akda ang kaugnayan ng nangyayaring antagonismong pang-uri sa pagitan ng mga maggagawang bukid at ng mga panginoong may lupa at sa pagitan ng estadong nagsisilbing pangil ng mga burgesya komprador at ng mga magsasakang pinagkakaitan ng lupa. Sa huli, hindi nakonkretisa ng texto na ang historikong ugat ng lahat ng panlipunang tunggalian ay ang pagkakabalahura pa din ng sambayanan sa isang malapyudal at mala-kolonyal na kalakarang panlipunan. Sa kasamaang palad, nalimita na lamang ang pelikula sa pagpoposisyon ng kanyang biswal na pag-iimahe at pakikidiskurso sa makitid na lente ng binarismo: pesante vs militar, usaping pang lupa vs militarisasyon, pasibo vs rebolusyonaryo.

Sa loob ng akda, naging abstrakto ang isang tyak na usapin gaya ng armadong pakikibaka at matagalang digmang bayan. Abstrakto sa kadahilanang hindi nailalatag ng masiste ang batayang pundasyon ng tunggalian, pakikitunggali, at ang pinakamataas na uri ng pakikidigma para sa panlipunang kasarinlan. Walang rasyonalisasyon kung bakit may pangangailangang humawak ng armas upang balikatin at baliktarin ang sistemang gumagapi sa inaalisputang uri. Sa loob ng texto, tila ang pagsapi sa rebolusyon ay itinutulak lamang ng idea ng "paghihiganti" at "pagbawi" sa halip na magsilbing imepratibo upang mabago-hindi lamang ang pangaabuso ng mga militar-kungdi ang isang sistemang nagbibigay lisensya sa pang-aabuso, militarisasyon, at maka-uring paghahari ng iilan at ng mga 
imperyo. Ang kakulangan na ito ay bunsod ng sinasabi ni O’Shuaghnessy (2007) na "reconnecting the violences of the margins to the systemic" (p. 3).

Malabnaw ang ideolohikal na pundasyon ng pelikula at maiuugat ang kakulangang ito sa labis na pagsandig din ng pelikula sa halina ng burgis na avantgardismo. Mas binigyang importansya sa pelikula ang pagiging masining nito sa halip na sabayang hasain ang kasiningan at katiningan ng politika ng texto. Ibig sabihin, dahil sa kalabisan ng mga poetikong elemento at mga abstraksyon, humina ang disin sana'y potensyal nito upang magsulong ng politikal na opensiba upang malalimang maipakilala ang tunay na diwa at adhika ng rebolusyonaryong pwersa.

Sa huli ay mapapaisip ka kung para sa masa nga ba ang akda o para sa mga burgis na manonood sa mga art houses at film festivals? Mapapatanong ka din kung rebolusyon nga ba ang isinusulong nito o rebolusyon lamang sa larangan ng estetikong pananagisag gamit na sangkalan ang tunay at nagpapatuloy na digmang bayan?

Ika nga ng Maoistang si Alain Badiou (2013), "[f]or our new bourgeoise, the masses are the subject matter of their project rather than its source-a mere role, a subjugated force, rather than a creative thought" (p. 38). Ang puna na ito ni Badiou ang marapat sanang tinahak na landas ng pelikula kung saan malinaw sanang nailahad na ang masang api ay nag-aaklas bilang kolektibong puwersa upang baligtarin ang sistemikong pagkakagapi sa ilalim ng isang mala-pyudal at mala-kolonyal na lipunan. At kung saan ang matagalan ng digmang bayan ay isang malikhaing kaisipan na may materyalisasyon sa larangan ng "tunay" at nagpapatuloy na pag-akda ng kasaysayan mula sa laylayan at lakas ng uring inaalipusta.

\section{Sa Ngalan ng Tubo at ang Isang Lipunang Mala-Pyudal}

Kung paghahambingin ang Red Saga (2004) at Sa Ngalan ng Tubo (2005), mahihinuhang magkahalintulad naman ang nais nitong puntiryahin. At ito ang problema sa usaping agraryo, dagok ng militarisasyon, usapin ng pyudalismo, at ang kondisyon ng posibilidad na maaaring mailuwal ng pakikitunggali at paghihimasik.

Ngunit kaiba sa konseptuwal na atake ng Red Saga, ang dokumentaryo ng Tudla ay sumandig sa tradisyunal at kumbensyunal na uri ng dokumentaristikong paglalahad. Gumamit ito ng voice over upang mailatag ang historikal na kontexto ng problema sa lupa at pang-aapi sa mga manggagawang bukid sa ilalim ng mga panginoong maylupa sa katauhan ng pamilya Cojuangco. Ipinaloob din sa voice over ang pagtatala ng kawalang materyalisasyon ng CARP (Comprehensive Agrarian Reform Program) maging sa ilalim ng dating pangulo ng republika na si Corazon Cojuangco Aquino. Inihapag din rito ang dahilan kung bakit naganap ang piket. At 
ito'y upang magkaisang ipanawagan at hamunin ang mga panginoong maylupa na tugunan ang makatwirang hinanaing ng mga magsasaka ng Central de Azucarera de Tarlac_-pagtataas ng sahod, karagdagang trabaho, at pagbabalik ng lupang kinamkam sa kamay ng mga magsasaka.

Sa loob ng dokumentaryo, aktuwal na saksi ang kamera sa marahas na dispersal ng mga nasa piket line na isinagawa batay na din sa sabwatang puwersa at koordinasyon ng kapulisan, militar, pamilya Cojuangco, at pambansa-estado sa ilalim ni GMA. Sa bahaging ito ng dokumentaryo, hindi hiwalay na aspekto ang galaw at masid ng kamera sa nasasaksihang pandarahas. Bagkus malinaw na makikitang kahanay ng mga dinadahas at nag poprotesta ang perspektiba ng kamera at ang may hawak nito.

Batay sa ganitong subhetong posisyon ng kumukuha, naipapasa ng kamera sa manonood, hindi lang ang masid, kungdi mas pa ang biswal na papapadanas sa manonood ng karahasan at kalupitang sinapit ng mga manggagawang bukid sa ilalim ng puwersa ng estado at panginoong maylupa. Walang pretensyon na umako ng posisyong neutral ang kamera sa kanyang pagkuha sa aktuwalidad. Sa halip, malinaw na makikita na ginamit ang kamera upang makiisa sa prente ng mga nagpoprotestang manggagawang bukid.

Dahil sa puwesto ng kamera, lantad na naipakita ang hidwaan sa pagitan ng mga nagtutunggaling puwersa at uri. Biswal na naipakita ng mga kuha ang polaridad sa pagitan ng mga kasapakat ng mga naghaharinguri at estado (kapulisan at militar) at ang hanay ng inaalisputang uri. Ang pandarahas na pinasasaksi at ipinadanas ng dokumentaryo ay kumitil sa 7 buhay, nagresulta sa halos 40 kataong nasaktan, 120 na iligal na pag-aresto, at ilan pang buhay na kinitil makaraang maisagawa ang dokumentaryo. Ang tindi ng karahasang sinapit ng mga manggagawang bukid sa Tarlac ay nagpapakita sa atin kung hangang saan ang kayang gawin ng mga naghahari upang masagkaan ang anomang uri ng pagkilos tungo sa mas makatwirang kaayusang panlipunan.

Gumamit din ang dokumentaryo ng mga talking heads. Ipinaloob dito ang salaysay ng mga kamag-anak ng mga biktima ng masaker. Madidinig dito ang kuwento ng mga ordinaryong manggagawang bukid na naging bahagi ng isinagawang piket. Pinagsalita din ang mga nasaktan sa kaganapan. At higit sa lahat, binigyan ng tinig ang mga naiwang magsasaka sa Hacienda Luisita upang ipakita na nagpapatuloy ang laban upang makamit ang hustisya at upang mawakasan ang mala-pyudal na kalakarang panlipunan labas sa kayang saklawin ng dokumentaryo.

Sa pagbibigay halaga ng dokumentaryo sa tinig ng mga nilalapastangan, nabigyan nito ng diwang maka-uri ang imahe ng mga manggagawang bukid sa loob ng texto. Ibig sabihin, malinaw na naipakita ng akda ang kalagayang 
pang-uri ng mga masasaka sa ilalim ng mga ganid na panginoong may lupa at mga kapitalista. Ang kanilang mga tinig ay nasilbing historikal na batis at testimonyo ng pagkamulat at pakikitunggali laban sa isang sistemang pumapabor lamang sa iilang pumipiga sa lakas ng uring anak pawis.

Nagsilbing historikong tinig ang mga salaysay ng mga magsasaka sa akda upang sabayang maisiwalat ang nagdaan, ang naganap, at siyang nagaganap pa ding inhustisya sa kay raming manggagawang bukid sa bansa mula noon hanggang ngayon. Batay sa aural at biswal na mga elemento nito, malinaw na nailahad ng texto ang kalagayan ng mga magsasaka hindi lamang sa Hacienda Luisita ngunit maging sa buong bansa. Isang kalagayang patuloy pa ding nakasukob sa isang mala-pyudal na kalakarang panlipunan na pumapabor lamang sa naghaharing iilan at sa imperatibo ng pagkamal ng kita. Hindi binitawan ng akda ang masisteng paglalahad sa tunay na ugat ng panlipunang tunggalian at ito nga ang malinaw na papapalutang sa usapin ng talaban ng uri bilang moog ng lahat ng kontradiksyong panlipunan.

Nasapul ng dokumentaryong Sa Ngalan ng Tubo (2005) ang esensya at diwa ng tunay na dokumentaryong politikal-may komitment sa inaalipustang uri, naipapakita ang ugat ng krisis panlipunan, naihahain ng malinaw ang tunggalian ng mga uri, nailalahad ang marapat na tugon sa krisis, at nagsusulong ng adhikang makamamamayan at mapanghimagsik upang mawakasan ang maka-uring sistemang ugat ng pambubusabos at pangduduhagi.

Sa huli, hindi lang ipinapalabas ang buhay at danas ng masa sa dokumentaryo, may panghihikayat ito sa manonood na makiisa upang mabago ang naipakitang kinapapaloobang baluktot na sistema hindi lamang ng mga maggagawang bukid kungdi ng lahat ng bahagi ng lipunang ginagatasan lamang ng iilan.

Malinaw ang taya sa katotohanan ng dokumetaryo batay sa pagsasalansan nito ng mga biswal at aural na ebidensya. At ito ang pagpapakita ng katotohanang tunay at historikal ang pang-aalipusta sa hanay ng uring magbubukid. At ang lipunan natin ay nananatiling mala-pyudal. Hinango at may basehan ang mga ebidensyang inihapag sa obhetong realidad ng lipunan. Idinidiin din sa dokumentaryo na may tunggalian sa lipunan at marapat at makatwiran lamang ang makitunggali sagpakat may mali at marapat na igiit ang tama. At ang diwang ito ang tinutukoy ni Rabinowitz (1994) na imperatibong moral ng anomang politikal na dokumentaryo, aniya " $[t]$ he documentary, then, is meant to instruct through evidence; it poses truth as a moral imperative" (p. 17).

Kung ang Red Saga (2004) ay abstraksyon sa konkreto, ang Sa Ngalan $n g$ Tubo (2005) ay nagsisilbi namang "sinema ng alaala" (Rabinowitz, 1994, p. 17) na nagpapakita ng aktibong pakikilahok ng mamamayan sa pag-akda 
ng kasaysayan. Ipinapaalala din nito sa manonood na ang problemang pang agraryo ay lantay na sa ating lipunan dahil na din sa maka-uring interes ng mga nagmamay-ari sa lupa, ng isang estadong lulong sa opio ng kapital, at lipunang mala-pyudal at mala-kolonyal. Nagsisilbing isang anyo ng interupsyon at interbensyon sa meta-naratibo ng huwad na pambansang kaunlaran ng estado ang naturang dokumentaryo. Ang ganitong uri ng kultural na texto ang tinutukoy ni Gutta (2011) na pangangailangan ng isang lipunang naghahangad ng pagbabago, ika nga niya "[e]ssential to the idea of social change therefore is the construction of departures from the accepted configuration of society, as a process that challenges the hegemony of the mainstream" (p. 4).

Hindi maikakailang parehong may sulong na intensyon ang Red Saga (2004) at Sa Ngalan ng Tubo (2005) upang ibuyangyang ang sinasapit ng mga nasa laylayan at upang maglatag ng mga alternatibong praxis upang sagkaan at lansagin ang naturang sistemang ugat ng pagkakaalipin ng sambayanan.

Sa panahon ng ligalig at impunidad, partikular sa ilalim ni GMA, ang $S a$ Ngalan ng Tubo ang malinaw na may gagap sa papel na marapat gampanan ng dokumentaryo at sining. Nang isang uri ng sinematikong interbensyong masasabi nating tunay na mula sa masa at para sa masa. At ito ay upang magsilbing gatilyo ng pagmumulat, pag-oorganisa, at pagpapakilos. Dahil sa panahon ng digma, kailangang sumandig ang manlilikha sa larangan ng 'politikal' at hindi lamang sa halina ng kasiningan at experimentasyon. Ito'y sapagkat sa panahong ginagawang abstrakto ng estado ang mga konkretong karanasan ng tao, ang abstraksyon sa konkreto ay pumapabor sa estado at hindi sa tao.

\section{PNOY, Daang Tagilid, at mga Dokumentasyon sa Kahirapan at Rebolusyon}

Ipinakete ng rehimen ni Benigno Aquino III (PNOY)ang mantra ng pamamahala nito sa idea ng "Daang Matuwid." Ginamit niya itong tungtungan upang linlangin ang mamamayan sa kunwa'y bagong demokrasyang hatid ng kanyang termino. Ngunit sa katunayan, gaya din ng pamamahala ni GMA, ang iniimbisyong daang matuwid ni PNOY at ng mga dilawan ay pumabor lamang din sa interes ng naghaharing uri at global na adyendang neoliberal (IBON Media at Communications, 2016).

Ipinagpatuloy ni PNOY ang pag-atake sa mga aktibista at mga kasapi ng mga kilusang ng pagbabago batay sa institusyonalisasyon ng Oplan Bayanihan (Umil, 2011). Nagresulta ang kampanyang ito ng 333 biktima ng extra judicial killings, 29 na sapilitang pagkawala, 248 na biktima ng tortyur, 1177 na iligal na detensyon, at 209, 768 na kaso ng pananakot at intimidasyon (Karapatan, 2016). 
Sa buong panunungkulan ni PNOY, maitatalang may 11, 768 na kaso ng demolisyon at sapilitang pagpapalayas sa sektor ng maralita (Karapatan, 2016) ng walang maayos at makataong lugar ng relokasyon. Sa panunungkulan din ni PNOY naging masidhi ang atake sa mga katutubong Lumad. Patunay dito ang pandarahas na sinapit ng mga guro ng ALCADEV, isang paaralang alternatibo para sa mga Lumad, sa ilalim ng mga militar na inatasang isakatuparan ang laban kontra insurhensiya (Karapatan, 2016).

Bilyong pondo din mula sa kaban ng bayan ang nawala at nakulimbat sa mga ahensya gaya ng DSWD, DOJ at DA (Karapatan, 2016). Idagdag mo pa dito ang milyong dolyar na relief funds para sa mga biktima ng bagyong Yolanda na hindi na nakarating sa mga nasalanta hanggang sa kasalukuyan. Korapsyon sa kaban ng bayan ang naging kagawian ng mga dumadambana sa daang matuwid.

Bahagi din ng anti-mamamayang mga polisiya ng administrasyong PNOY upang sukdulang ipaloob ang adyendang neoliberal sa buhay ng mamamayan ang pagdidisenyo ng programang $\mathrm{K}-12$, ang pagtataguyod ng mga bagong central business districts gaya ng BGC, at public-private projects. Ito'y mga pang ekonomiyang proyekto na hindi nagbibigay ng proteksyon sa mamamayan. Ang pinapaboran lamang ng mga polisiyang ito ay ang pangangailangan ng negosyo at global na pangangailangan kaugnay ng lakas paggawa.

Kung susumahin ang daang matuwid, nagresulta lamang ito sa labis na paghihirap ng mamamayan, pagpapatuloy ng paglabag sa karapatang pantao, militarisasyon, korapsyon, mga polisyang pumapabor sa interes ng negosyo, at ang kawalan ng tunay na pagbabago.

\section{Tundong Magiliw at ang Bitag ng Cinema Verité}

Ang usapin ng labis na kahirapan ang sentral na paksa at inilalahad ng dokumentaryong Tundong Magiliw (2011) ni Jewel Maranan. Tumatawid ang dokumentaryo mula sa panahon ng pamamalakad ni GMA hanggang sa unang taon ng pamumuno ni PNOY noong 2011. Kung poetiko ang naging atake ng Red Saga at kumbensyonal naman ang sa Sa Ngalan ng Tubo, pag sangguni naman sa tradisyon ng cinema verité ang piniling anyo ni Maranan upang maipakita ang pang-araw-araw na kalbaryo ng isang pamilya sa Tondo na gagad sa kadahupan at paghihirap ang buhay.

Pinatutunghay tayo ng masid ng kamera sa pagharap ng naturang pamilya-mula sa ina, ama, hanggang sa mga anak nito-sa araw-araw na pakikipagbuno nila sa mundong ang simula't pagtatapos ng araw ay kakambal na ng paghihirap. Makikita sa dokumentaryo ang samu't saring pagbabakasakali ng pamilya upang kahit papaano'y makaagapay sa hirap ng buhay. Nariyan ng mamansing sila sa maduming ilog upang kahit papaano'y 
may maiulam sa araw na iyon. Makikita din silang nagsasalo sa pinagsamang luma at bagong kanin bilang pinag-ubrang pananghalian. Masasaksihan din natin ang mumunting kaligayahan ng mga anak sa gulagulanit na pabalat ng mga DVD na nasisilbing pagkakaaliwan sa kabila ng kasalatan. Kasama tayo sa mga gabing gasera lamang ang ningning ng tahanan. Masasaksihan din natin sa huli ang panganganak mismo ng ina sa naturang bahay dala na din ng kasalatang pampinansya. Ganito ang buhay ng pamilyang sinubaybayan ni Maranan sa kanyang dokumentaryo na marahil ay hindi kalabisang sabihin ang siyang buhay ng kay raming Filipino na nasasadlak sa kahirapan.

Nilalambongan ni Maranan, sa pamamagitan ng editing, ng mga poetikong interjeksyon ng mga cut away ang pelikula upang magsilbing mga kontra-imahe sa tila kawalang kaunlarang buhay ng pamilya. Sentral na imahe sa pelikula ang pabalik balik at paulit-ulit na pagpapakita ni Maranan sa mga cargo crates sa pier. Minsan ay bilang banahi ng mise-enscene, minsan ay bilang B-Roll.

Hindi mahirap makita ang intensyon ni Maranan sa paggamit sa naturang imahe. Una, upang ipakita ang kabalintunaan at kontradiksyon sa pagitan ng mga mamamayang lugmok sa kahirapan at ng isang bansang ang idea ng kaunlaran ay nakabatay sa daloy ng kalakal, komoditi at imepratibo ng negosyo. Ikalawa, sa kaisa-isang caption ng pelikula, kung saan ang authorial na boses na ng umakda ang nagsasalita, malinaw ang punto na nais patimuhin ni Maranan - aniya ng kapsyon sa huli,"[s]a panahong ginagawa ang dokumentaryong ito, sabay na lumalakas ang alingangaw ng mga barko't kahong bakal ng mga banyagang kalakal na dumaragsa sa pantalan sa Tondo at ang bantang nakaamba sa mamamayan nito."

Bagamat layong ilahad ni Maranan ang usapin ng kahirapan sa isang anyo na pumopostura bilang obhetong pagtatala sa "dalisay na sinematikong katotohanan" (Rabinowitz, 1994, p. 20) na kinakaptyur ng kamera, kailangang makitang natisod si Maranan sa limitasyon ng estilong verité.

Sa bahaging ito, mahalagang balikan ang masisteng puna ni Rabinowitz (1994) sa kahinaan ng verité sa kakanyahan nitong kritikal na makapaglatag ng katotohanan, aniya " $[\mathrm{w}]$ hen documentarians began to experiment with living cinema, cinema verité, direct cinema, documentaries again attempted to capture a pure cinematic truth... Was the point of documentary merely to record, or instead recast, the visible and audible world through the cinematic apparatus" (p. 20). Sa kaso ng Tundong Magiliw (2011), hindi makasasapat ang pagpapakita lamang ng pang-araw-araw na buhay ng mahirap upang maipaunawa sa manonood, lalo na sa mahihirap, kung bakit nga ba sila naghihirap. Sa loob ng texto, walang pagtatangkang mailantad kung ano nga ba ang basehang materyal-ibig sabihin ay historikal at sosyoekonomikong dahilan—ng kahirapan. 
Kung gayon, ang "katotohanan" na ipinapakita ni Maranan sa kahabaan ng dokumentaryo ay limitado lamang sa makitid na bista ng literal na pagrerekord ng buhay ng pagiging mahirap. Sa isang lipunang lampas isang porsyento lang ang may mariwasang buhay at kalakhan ng populasyon ay araw-araw na hinaharap ang kahirapan, higit na magiging mainam at mapanuri siguro kung maipapaabot sa kapus palad na hindi tadhana ang pagiging mahirap bagkus ay resulta ng nananaig na gitgitan sa pagitan ng uring pinakaitan at ng isang sistemang pumapabor sa uring nakikinabang.

Tinangka ni Maranan sa huli na itagni ang usapin ng kahirapan sa paguugnay nito sa pagdatal ng mga kalakal sa pier. Ngunit hindi malinaw ang sinasabi niyang banta nito sa mga tiga-Tondo o mahihirap. Hindi malinaw dahil hindi naihayag sa loob ng pelikula ang iniaangat na punto sa huli. Banta saan nga ba ang tinutukoy niya? Mapapatanong ka tuloy kung ano pa ba ang maaaring maging banta sa mga taong lugmok na sa kahirapan? Ano nga ba ang dapat na gawin ng mahirap upang mabago ang buhay nilang araw-araw ay tila pakikipagsapalaran sa kawalang katiyakan? Naipaalam ba ng pelikula ang dialektikal na ugnayan ng kapital sa kahirapan? Para sa mga mahirap nga ba ang likha o ginamit lamang ang buhay ng pagiging mahirap upang ihapag sa mga mausyosong masid ng mga nasa hanay ng gitnang uri?

Politikal na usapin ang kahirapan at may kontextong historikal at sosyo ekonomiko. Ang dialektikal na diskursong ito ang nawaglit sa dokumentaryo. Muli, sasangguni ako sa argumento ni Rabinowitz (1994);

One of the critiques fired at the direct cinema movement was its lack of social context-its naturalizing of the viewing process or, in Benjamin's words, its lack of caption. The body represented by documentary films, claims Bill Nichols, must be understood in relation to a historical context which is a referent, not on ontological ground. History is where pain and death occur but it is in representation that the facts and events gain meaning. (p. 21)

Sa ganang akin, ang pagpapakita sa mahirap at kahirapan, ng walang interbensyon upang ikontextualisa ito, ay isang uri ng naturalisasyon at normalisasyon sa mismong usapin ng kahirapan at buhay ng mga naghihirap. Dehistorisado at dekontextualisado sa dokumentaryo ang usapin ng kahirapan sapagkat iniwasan ng manlilikha na mamagitan sa talaban ng diskurso at ideolohikal na posisyunan liban sa huling kapsyon ng pelikula. Bagamat naipakita at naipaamoy sa atin ng dokumentaryo ang buhay at pakiramdam ng pagiging mahirap, hindi nito kritikal na siniyasat ang politika sa likod ng patuloy na marhinilisasyon ng mga maralitang tiga lunsod. 
Bagamat napapanood natin ang "buhay" ng mga mahirap. Naririnig natin ang kanilang mga daing. Naaantig tayo sa tuwing nasasaksihan ang kanilang mga danas. Napapangiwi tayo sa kanilang dahop na kalagayan. Sa huli, lahat ng iyon ay nararamdaman natin sapakat sinisilip lang natin sa iskrin ang kanilang buhay. At dahil tila natural na nagaganap sa harap natin ang lahat, hindi natin naaalintanang ang ipinapatanggap na mismo sa atin ng dokumentaryo ay ang buhay ng pagiging mahirap at ang kawalan ng kontextong panlipunan ng diskurso ng kahirapan.

At dahil kimi sa politikal at ideolohikal na interbensyon ang dokumentaryo, sa huli'y nananatiling mga tauhan lamang ng isang palabas ukol sa kahirapan ang mga tunay na buhay na taong sinubaybayan nito. Walang minomobilisang oposisyunal na tinig ang dokumentaryo. Ito man ay mapa sa loob ng pelikula at maging sa labas na ng filmikong mundo. Mainam na balikan ang payo ni Martin O’Shaughnessy (2011) kaunay ng usaping ito, aniya;

In the face of this silencing, the capacity of films to make the voice of the voiceless heard and to constitute them as political agents and not as social objects for our voyeuristic or 'humanitarian' contemplation would seem a central concern of critical analysis. (p. 4)

Sa kasamaang palad, nagmistulang mga obheto lamang ng voyuristikong masid ng kamera ang buhay ng mga mahirap sa loob ng dokyu. At dito na nga nabalahura ang dokumentaryo ni Maranan. Sa halip na mabigyan nito ng tinig ang mga mahihirap na matagal ng winaglitan ng boses ng isang sistemang anti-mahirap, naging paksain na lamang sila sa isang dokumentaryong salat sa mapanuri at maka-uring linya.

Matapos mapanood ang pelikula, ang marapat sanang pinopolitisang burgis na manonood at mismong hanay ng mahirap ay uuwing may bitbit na awa sa mahirap o sa sarili ngunit hindi kailanman papasok sa hinagap-ng manonood na burgis at ng mahirap—na kailangang maging mga kabahagi tayo ng mga pagkilos at kolektibong inisyatiba upang baguhin ang maka-uri at 'di makatarungang lipunang ito.

Sa huli, ang pagkagiliw ni Maranan sa verité ang salarin ng paglabnaw ng angking politikal na potensyal ng kanyang sinayang na materyal.

\section{The Guerilla is a Poet at ang Nostalgia sa Rebolusyon}

Ang ikalawang pelikula na nais kong suriin ay ang The Guerilla is a Poet (2013) nina Sari at Kiri Dalena. May tatak Dalena ang naturang obra-nagsasalimbayan ang reenactment, ang dokumentasyon sa mga testimonyo ng mga kinapanayam na tao, at may hagod ng experimental na 
biswalisasyon sa ilang bahagi ng pelikula upang sa huli'y magsanib ang lahat ng elementong ito sa pagbubuo ng holistikong naratibo hinggil sa buhay ng mga rebolusyorayong sina Josa Maria Sison at Julieta De Lima.

Nakabatay ang naratibo ng dokumentaryo sa testimonyo nina Joma at Julie ukol sa kanilang relasyon, sa pagkakatatag ng Partido Komunista ng Pilipinas at Bagong Hukbong Bayan, sa inkarserasyon nila sa ilalim ng diktadurang Marcos, sa ugnayan nila sa iba pang mga kasabayan sa kilusan gaya ni Bernabe "Kumander Dante" Buscayno, sa pahapyaw na silip sa buhay estudyante at underground (UG), at sa pagpapakita sa buhay nila bilang mga rebolusyonaryong napilitang mamuhay sa ibang bayan dahil inexile ng pamahalaang Aquino sa Netherlands.

Sa loob ng texto, nagsilbing sentral na metapora ang tulang Guerilla is like a Poet upang simulan at isara ang dokumentaryo. Gamit na salalayan ang talinghagang bitbit ng tula, layon nitong pagtagniin ang pagsasalimbayan ng pagiging makata ni Joma, ang kahulugan ng pagiging gerilya na siyang diwang isinusulong ng tula, at ang hindi maihihiwalay na persona ni Joma bilang makata, makatang mandirigma, at ang pagiging mukha ng itinatag na hukbong nagsusulong ng digmang bayan.

Hindi maikakailang awtobiograpiya ni Jose Maria Sison ang dokumentaryo. Isa itong uri ng malikhaing dokumentasyon na may intensyong gamitin ang mga oral na testimonyo at salaysay bilang pangunahing batis sa pagsasadula, pagbibigay katauhan sa pangunahing persona, at sa kaugnayan ng persona sa historikal na naratibo ng pagkakataguyod ng kilusang pambansa demokratiko at partido komunista ng Pilipinas. Kung kaya’t bukod sa pagiging awtobiograpikal, historikal na dokumentasyon at dokumentaryo din ito ng unang mga taon ng kilusan.

Ngunit sa kabila ng intensyong gawing humanisado ang pagpapakilala sa isa sa mga tagapagtatag ng bagong Partido Komunista na sabayang may layon ding basagin ang demonisadong depiksyon sa mismong partido ng popular na media at pambansa estado, hindi maikakailang may ilang bagay na hindi nailahad ang pelikula na masasabing nagpapusyaw sa radikal na potensyal nito. Isa sa mga ito ang kawalan ng direktang paglilinaw at pagpapa-unawa sa esensya at diwa ng kilusan, ng isinasagawang digmang bayan, at higit sa lahat ay ang paghahain ng mga kaisipang nagsilbing mga sentral na ideolohikal na giya ng partido. Hindi nailahad ng may linaw at lalim kung bakit nga ba kailangang buwagin ang lipunang mala-kolonyal at mala-pyudal. Hindi din nailinaw ang kahalagahan ng paghawak ng armas upang maging kaanib sa tinatawag na pang matagalang digmang bayan upang sa gayon ay makalaya ang mamamayang Filipino mula sa tanikala ng imperyalismo at sistemang mala-pyudal at mala-kolonyal. 
Bagamat paminsan minsan ay nababanggit ang mga ito-sa mga reenactment at panayam-hindi makakasapat ang mga pahapyaw na pagbanggit lamang sapagkat ang mga kaisipang ito ang marapat sanang binibigyang diin at elaborasyon ng dokumentaryo pelikula. Kailangang mabatid na ang kalakhan ng manonood nito'y estranghero sa mga naturang konsepto, kaisipan, at idea. At kungdi man estranghero ay mga matagal ng isinara ang tainga sa mga "ismo" sapagkat nasalamangka na nga ng reaksyunaryong estado upang maniwalang kalaban ng mamamayan ang kilusan para sa panlipunang pagbabago. Pagkakataon sana ang obra nila Dalena upang banggain ang mistipikasyon sa sosyalismo, komunismo at mga komunista. Mga pagbanggang maaaring makapagbigay linaw sa puso at adhika ng kilusan, mga pagbanggang may layong makabig ang puso't diwa ng nakararami. Ngunit hindi ito napagtaumpayan ng kabuuang istruktura ng pelikula.

Dahil sa kakulangan ng pagpapalawig sa mga kaisipan ng kilusan sa loob ng sinematikong texto, nagiging hungkag na sagisag na lamang ang mga eksenang dapat sana'y may bigat at lundayan upang maipakita ang simulain, kaibutaran, at prinsipyong tangan ng mga unang sumabak sa digmang bayan. Halimbawa na lamang nito ang mga eksena ng pagsasanay ng hukbo, pakikidigma ng mga kadre, pag-awit ng mga rebolusyonaryo, at mapagpalayang tingin ng hukbo sa kasarian. Dahil salat sa kontextualisasyon at historisasyon, ang mga eksenang ito'y masasabing halos walang ipinagkaiba sa mga komersyal na pelikulang nagtangkang isapelikula ang Bagong Hukbong Bayan. Romantisado ang lapit at isang artefact na lamang ng nagdaan ang kilusan. Ang likha nila Dalena ay nabalahura na lamang sa opio ng nostalgia.

Hindi nailapit ng pelikula sa manonood at naiugnay sa kasalukuyang kalagayang panlipunan ang idea ng rebolusyonaryong kilusan at pagiging rebolusyonaryo. Una, dahil tila fosilisadong naratibo lamang ito ng nagdaan at ni walang pagtatangkang ipakita na nagpatuloy at nagpapatuloy ang rebolusyonaryong laban hanggang sa kasalukuyan. Ikalawa, na makikita sa montage sa huling bahagi ng pelikula kung saan dramatikong binabasa ang tulang Guerilla is like a Poet. Bagamat'may pagtatangkang magmula sa hanay ng magkakaibang uri ng tao ang pagbabasa ng mga saknong mula sa tula, tinapos pa din nila Dalena ang montage sa pagbabasa ng batang Joma ng huling bahagi ng piyesa. At ang pagsasarang ito ang isa sa mga ideolohikal na problema ng pelikula.

Bagamat nakabatay sa talambuhay ni Joma ang akda, mahalagang mabatid na hindi maihihiwalay ang personal sa larangang politikal at diskursong historikal. At ang isa sa adhika ng sinomang rebolusyonaryo ay ang pagtataguyod ng lakas ng kolektibo at hindi ng indibidwal lamang. 
Ang pelikula ay ukol kay Joma. Ngunit ang buhay ni Joma ay kakambal ng rebolusyon. At ang rebolusyon ay binubuo, hindi lamang ni Joma, kungdi ng kay raming hanay ng mga anak ng sambayanan noon hanggang sa ngayon.

Ang pagsasa ngayon ng rebolusyon, paghulagpos sa fiksasyon sa ikonograpiya ni Joma, at diin sa kolektibong katangian ng kilusang mapagpalaya at digmang bayan ang nawaglit sa dokumentaryo pelikulang ito. Ibig sabihin, bagamat tungkol sa buhay ng komunista ang texto, tila ang naglaho sa pelikula ay ang kolektibong diwa ng sosyalismo. Nagkulang ang dokumentaryo sa pagtatawid ng diwa ng rebolusyon sa kontexto ng lipunan at kontemporaryong henerasyon-upang sana'y magsilbing ebidensya na wala namang ipinagkaiba ang noon at ngayon at kung gayon makatwiran pa ding maghimagsik. Dahil ito naman sana ang dapat na tungkulin ng mga dokumentaryong politikal ukol sa kasaysayan. Aniya nga ni Rabinowitz (1994), "[t]he historical documentary not only tells us about the past, but asks us to do something about it as well-to act as the Angel of History and redeem the present through the past" (Rabinowitz, 1994, p. 26).

Sa panahon ng labis na pagdarahop ng mamamayan batay sa panunuot ng mga polisiyang anti-mamamayan at patuloy na pagsalanta sa mga mamamayang kaisa sa kilusan ng pagbabago noong panahon ni PNOY, mas lalong kinakailangan ng mga sinematikong interbensyon na may talas at tapang na ilantad ang puno't dulo ng mga usaping sumasalanta sa sambayanang Filipino. Kung ang mga dokumentaryo ay sinasabing hindi lamang tala ng nagdaan ngunit ang tasitong tungkulin ay ang "pagpapanuot ng damdamin, pag-iisip, at pagkilos" (Rabinowitz, 1994, p. 8), masasabing nagkulang ang Tundong Magiliw (2011) ng siste upang turulin at tumbukin ang pambansa estado bilang salarin at tyak na may pananagutan sa patuloy na paghihirap ng mamamayan. Hindi din nahigit ng The Guerilla is Poet ang ginintuang opurtunidad na mailapit sa mamamayan ang kahalagahan ng paghihimagsik, hindi lamang bilang bahagi ng nagdaang danas ng bansa sa ilalim ng Batas Militar, kungdi bilang buhay na pwersa pa din ng pagkilos at pababago ng lipunan sa kasalukuyan.

Sa mga panahon ng ligalig, mas mainam na isagad ang politika ng texto sa halip na mag-alangan at mag-alinlangan, dahil ang hindi pagsagad sa diskurso ay palagian lang ding pagpabor sa limitasyong itinakda ng isang reaksyunaryo at pasistang estado.

\section{Rehimeng Duterte:}

\section{Textual na Mediasyon sa Isang Panahong ang Lahat ay Pinapaslang}

At ngayong lumampas na nga tayo sa ikalawang hati ng termino ni Duterte, heto ang ilan sa mga isyung bumabalot sa kanyang administrasyon: 
tinatantyang 22,983 na ang napaslang dahil sa Oplan Tokhang (Human Rights Watch Philippines, 2019); umabot na sa 222 ang bilang ng mga biktima ng EJK mula sa mga sektor (hal: manggagawa, pesante, guro, kultural na manggagawa, estudyante, lumad, mamamahayag, mangingisda, pari, abogado, katutubo, environmentalist) na pinaghihinalaang kalaban ng estado kasama na nga rito ang mga martir tulad nina Atty. Ben Ramos at Randy Malayao (Karapatan, 2019); patuloy na pagkakaroon ng Martial Law sa Mindanao na nagbunga na kay raming kaso ng paglabag sa karapatang pantao; pagkitil sa usaping pangkapayapaan; halos 447,963 na kaso ng forced evacuation (Karapatan, 2019); patuloy na panghihimasok ng Tsina sa pang karagatang sakop ng bansa sa kabila ng pagkapanalo natin sa kasong arbitrasyon sa Hague (Asia Maritime Transparency Initiative, 2019); patuloy na panggigipit sa mga Lumad at sa mga gurong nagtuturo sa mga alternatibong paaralan; tinatayang 85,236 na kaso ng pananakot at intimidasyon (Karapatan, 2019) sa mga organisasyon at taong kinahon na bilang kalaban ng estado kabilang na nga dito ang mga organisasyon gaya ng ACT Teachers Party List, KMU, Gabriela, at Altermidya; humigit kumulang 3.6 milyon na kabataang out of school youth (PSA, 2019); paglilibing sa diktador na si Marcos sa libingan ng bayani sa ngalan ng historikal na rebisyonismo (Esmaquel II, 2016); panggigipit sa mga institusyong pang media na kritikal sa administrasyon gaya ng sinapit ni Maria Ressa (Lee, 2020); pagbibigay diin sa iskema ng edukasyong layong lumikha ng mga "skilled laborers" upang tugunan ang kahingian ng pandaigdigang marketo na malinaw na makikita sa imperatibo ng programang K-12 ng DepEd at sa pagkaltas naman ng CHED sa mga asignaturang Filipino at Panitikan (Rodriguez at Pangilinan, 2019); at idagdag mo pa ang banta sa karapatang pantao ng nakaambang papapasa ng Anti- Terror Bill (Educators Forum for Development, 2020).

Pananakot at pagpaslang ang pangunahing wika ng "pasistang" (Imbong, 2020)rehimen ni Duterte. Sa ilalim ng panunungkulan nito, kawalang pagbabago sa buhay ng mamamayan at sambayanan ang hatid nitong sumpa. At mula sa ganitong kontexto ng lipunan ko nais siyasatin ang diskursong hatid ng dokumentaryong Yield (2018) hinggil sa ugnayan ng kahirapan at mga panlipunang puwersa gaya ng pambansa estado.

\section{Yield at ang Diskurso ng Pagiging Miserable}

Humigit kumulang limang taon ginawa ang nina Tagaro at Uriu ang dokumentaryong Yield (2018). Gaya ng Tundong Magiliw (2011), tungkol ito sa kahirapan at istilong cinema verité ang pinaborang anyo ng paglalahad nito. 
Sa kahabaan ng dokumentaryo, sinundan at sinubaybayan nina Tagaro at Uriu ang buhay ng ilang kabataang kumakaharap sa mga hindi makataong kondisyon dulot ng labis na kahirapan. At heto ang buhay ni Jomar na naninisid at nagbabakasakaling makatisod ng mineral na ginto sa dagat, nina Alex at Glady Mae na parehong may hydrocephalus, ni Edralen na sa kabila ng kahirapan ay masigasig na pinapasok ang mga bagay bagay upang kahit papaano'y makatawid sa pang-araw-araw, nina Rommel, Ariel at April na mga child laborers sa tistisan ng bato, ni Jason na dahil sa pagbubuhat ng bulto ng mga gulay ay naapektuhan na ang gulugod, at ni Essam na lumabas sa huling bahagi ng dokumentaryo bilang mag-aaral at batang may tangan tangang baril.

Intensyon ng dokumentaryo na ipakita ang labis na pasakit at exploytatibong kondisyon na kinakaharap ng mga kabataan, maging ng kani-kanilang pamilya, sa ilalim ng isang relasyong panlipunang patuloy na dumudusta sa abang-uri. Masining na ipinapakita ng masid ng kamera, sa pamamagitan ng malinis na mga komposisyon ng kuha at mga imahe, ang pakikipagbuno sa kadahupan ng mga sinusubaybayang persona sa naratibo. Ngunit sa kabila ng ganda ng sinematograpiya, hitik na mise-en-scene, malinis na editing, at husay teknikal nito, ang hindi natalakay ng texto ay ang mismong panlipunang ugat ng paghihirap ng mga kabataan at kahirapan sa pangkalahatan. Kung gayon, sa kabila ng lahat ng kagandahang teknikal na ipinamalas ng dokyu, ang hindi nito napuntirya ng may siste ay ang salimuot ng kahirapan bilang usaping panlipunan na resulta ng talabang pang-uri at ng isang sistemang pumapabor lamang sa nagsasamantalang uri.

Sa katunayan, pinatutunghayan lamang sa atin ng dokumentaryo ang mga buhay at katawang gagad sa kahirapan bilang mga obheto ng ating mga maurirat na masid. Ipinapakita ng dokyu sa manonood ang kanilang pangaraw-araw na buhay, ipinapadama ang kanilang mga pagod, ipinapatagos sa damdamin ang kanilang mga pighati, at ipinapasaksi sa atin ang kanilang mga pagsuko't pagtitiis. Subalit ni minsan ay hindi natin maririnig ang kanilang tinig at saloobin kaugnay ng buhay na kinapapalooban nila. Sa loob ng texto, inilalahad sa atin ang docility ng mga tauhan sa isang banda ngunit ginagawa din naman silang docile na mga subheto ng dokumentaryo sa ikalawang malas. Ang nagsasalita sa dokyu ay ang mga napiling imahe mula sa mapanilip at mausisang mga mata ng lumikha. At mula dito, inaakay tayong silipin ng walang bahid ng subhetibong intensyon ang buhay na malayo sa ating mga danas. Sa madaling sabi, voyueristiko ang pelikula sa mga mahirap. At tayo ang naninilip dito.

Isa sa dahilan ng ganitong kahinaan ay ang mismong estilo ng exposisyon na pinaboran ng mga lumikha. Isang estilong nagsisiwalat din mismo sa ideolohikal na tindig ng mga manlilikha kaugnay ng kanilang pananaw 
panlipunan hinggil sa usapin ng kahirapan. Nais kong sumangguni kay Rabinowitz upang bigyang diin ang puntong ito, aniya, "[w]ithout the filmmaker present on screen, however, the camera's view is disembodied and so dehistoricized, while the filmed bodies are simultaneously overinvested with meaning yet deprived of agency" (Rabinowitz, 1994, p.21). Dahil sa idea ng verité ng kunwang distansasyon ng manlilikha sa paksa, ang kunwang ipinapakita lamang sa atin ay ang natural na pag-inog ng buhay ng ating mga pinapanood sa kabila ng kanilang mga kinakaharap. Kumbaga, ang nakikita natin bilang manonood ay ang siyang kunwang tunay. Subalit may kinakaltas at kinikitil ang ganitong estilo. At ang una na nga nitong inuumit ay ang pagkakataon ng mga persona sa texto na makapagsalita kaugnay ng kani-kanilang pagtatasa ukol sa kanilang buhay. At kung nawawalan ng pagkakataon ang mga persona sa dokyu na makapagsalita, nawawalan din ng tyansa ang manonood-liban sa pagtunghay sa mga beyutipikadong imahe ng kahirapan — na mahinuha ang mga panlipunang pwersa na dahilan ng paghihirap ng nakararaming mamamayan. Ang ikalawang winawaglit nito ay ang aktibong pag-uugnay sa manonood sa usapin ng kahirapan. Matapos mapanood ang buhay ng mahirap, ano na nga ba ang marapat nating gawin kung gayon bukod sa pumalakpak?

Ang winawaglit ng dokyu ay ang kakanyahan ng mga mahirap, at maging ng mga manonood, na magkaroon ng ahensya upang mabago, at hindi lamang upang tanggapin, ang hindi makataong panlipunang kondisyong kinapapalooban ng kay raming Filipino. Ang ahensya, ayon na din kay Dutta (2011), ay ang "capacity of human beings to engage with structures that encompass their lives, to make meanins through this engagement, and at the same time, creating discursive openings to transform those structures" (p. 13). Sarado ang dokyu sa pagbubukas ng mga siwang ng pagtutol at pabangga sa usapin ng kahirapan. Sa katunayan, ang kabuuang imahe na nililikha nito ay pagiging resilient ng mga mahirap. Nagtityaga kahit inaapi. Gumagawa ng paraan kahit pinagkakaitan ng sistema. Ngumingiti kahit araw-araw na nagdurusa. Tinatanggap ang hindi makatwiran. Ang resilient na imahe ng mga persona sa dokyu ay ang mismong katangian ng isang lipunang gusto ng estado. Isang lipunang naghihirap ngunit kayang magtiis at gumawa ng mga paraan sa kabila ng pang-aalipusta ng nangyayaring uri at sistema.

Isang halimbawa na nga lamang nito ay ang iniangat na usapin ng child labor sa dokyu. Bagamat biswal na ipinatutunghay sa manonood ang pasakit na dinaranas ng mga batang nagtatrabaho, huminto na lamang ito sa naturang exposisyon. Hindi na naipaliwanag ng may siste na ang usapin ng child labor ay hindi lang manipestasyon ng paglabag sa karapatang pantao ng kabataan ngunit indikasyon din ng panunuot ng lohika ng neoliberalismo 
hinggil sa paggawa. Isang exploytatibong makinarya na ipinatutupad batay na din sa suhay ng mga korporasyong lokal at multinasyunal na nagmamayari ng naturang mga negosyo at palaigang kasapakat ng pambansa-estado. Kung gayon, hindi lang moral na usapin ang child labor ngunit usaping pang ekonomiko din na sadyang hindi iniangat nina Tagaro dahil salat nga ang texto sa masisteng kontextualisasyon dahil na din sa limitasyon ng mismong estilong pinili nila sa paglalahad. Dahil na din sa makitid at reaksyunaryong tindig nila bilang manlilikha.

Gusto ko ding ilinaw na hindi totoong unobtrusive sa buhay at daigdig ng tao ang estilong verité. Iyon lamang ang nais nitong ipostura sa paningin ng mga manonood. Sa katunayan, ayon muli kay Rabinowits (1994), "[t]he idea of being unobtrusive was, as everyone realized, a fantasy-if nothing else-wires, microphones, camera and lights were continually present-not to mention their operators" (p. 20). At kaakibat ng obtrusyong ito sa buhay ng tao sa ngalan ng sinema ng katotohanan at sining, hindi maiiwasang may mga nahakbangang etikal na diskurso na siyang nagluwal pa ng mas maraming kontradiksyon imbis na kasagutan.

Dalawang eksena sa dokumentaryo ang nais kong ilatag bilang mga indikasyon ng kalabisan ng obtrusyon kungdi man kalabisan ng sinematikong lisensya upang walang pakundangang pasukin ang buhay ng tao sa ngalan ng huwad na realismo ng verite. Una na dito ang serye ng mga kuha kay Alex mula sa pagkakapasok sa ospital, sa paglala ng sakit, hanggang sa close-up habang impit ang tinig na inuusal na "pagod na pagod na ako," (Enouye, 2018, 1:10:43 at 1:10:51) hanggang sa kuha ng nanay ni Alex habang umiiyak sa harap ng ataol (Enouye, 2018, 1:09:57). Dahil sa lisensya poetika at paghahabol na makalabit ang emosyon ng manonoodupang lubusang maawa-sa sinapit ni Alex dala ng sakit at kahirapan, nakakapoot isiping ang pagdurusa mismo ni Alex ang kinasangkapan upang ipagduldulan sa manonood na namatay siya dahil siya ay mahirap at may kalunos lunos na buhay.

Sa bahaging ito ng dokumentaryo, mahalagang maitanong kung tunay nga bang ang dokumentaryong ito ay naghahangad na maipakita ang aping kondisyon ng mahirap o ito rin kaya ay isang uri ng exploytasyon sa inaping uri? Alam na dapat natin ang sagot doon.

Ang ikalawang eksena na nais kong ilatag ay ang yugto sa dokumentaryo ukol kay Jason. Dala ng pangangailangang kumita ng kahit katiting upang makataulong sa pamilya, tiniis ni Jason ang pagbubuhat ng sako-sakong mga gulay (Enouye, 2018, 0:05:41)kahit siya'y nasa murang edad pa lamang. Dala ng hindi makataong kondisyon na ito, bumaluktot ang kanyang gulugod. Dala ng kahirapan, hindi siya kaagad napatingnan sa doktor. Sapat na siguro ang mga ito upang maipakita ang epekto ng kahirapan sa mga tulad ni Jason. 
Ngunit hindi nakontento ang mga dokumentarista ng Yield. Gaya ng eksena kay Alex, binabad muli ang kuha ng kamera sa nangunguyapit at tila namamatay sa sakit na si Jason(Enouye, 2018, 1:07:23). Sa ngalan ng realismo at politikal na ekonomiya ng emosyon, ang ginawang manggagawa upang maihatid ang emosyon sa manonood ay ang naghihirap na katawan ni Jason. At kung gayon, muli kang mapapatanong, ang moral na tungkulin lamang ba ng mga dokumentarista ay ang makuhanan ang siyang nagaganap o maging kabahagi sa loob at labas ng pelikula upang mabago ang buhay ng naghihirap?

Lisyang-lisya din ang pasok ng batang may baril (Enouye, 2018, 1:26:30) sa huling bahagi ng pelikula. Hindi malinaw kung siya ay bahagi ba ng hukbo. At kung bahagi siya ng hukbo, hindi ba't bawal sa hukbo ang menor de edad. At kung hindi naman siya bahagi ng hukbo, bakit siya may baril at ano naman ang koneksyon nito sa pangkalahatang naratibo ng dokyu. Pinilit ang pasok nito upang maipakita ng dokyu na may mga kabataang iba ang landas na pinili kaugnay ng pagharap sa kahirapan. Ngunit dahil sa dulo na lamang ito basta bastang ipinasok, naging dekontextualisado ang katauhan ng persona.

Isang dokumentaryong pumoposturang para sa kapakanan ng mahirap ang texto nina Tagaro at Uriu ngunit hindi ko kailanman masasabing nadinig ko kahit pabulong ang impit na tinig ng mahirap sa loob ng texto. Ang diskurso ng kahirapan at pagiging mahirap sa loob ng dokumentaryo ay nakabatay sa dibuho ng burgis na masid ng mga dokumentarista. Hubad sa panlipunan, sosyo-ekonomiko, at historikal na kontexto ang kahirapang natutunghayan natin sa biswal na naratibisasyon ng akda. Isang depiksyon sa mga buhay ng mahirap na hubad sa politikal na diskurso ang ipinatutunghay sa atin. Sa katunayan, ang natutunghayan mismo natin ay ang maka-uring sipat ng mga lumikha sa isyu ng kahirapan. Isang sipat na mula sa mga uring malayo ang buhay sa karanasan ng mahirap.

Kung susumahin, walang ipinakitang bago ukol sa usapin ng kahirapan ang dokumentaryo. Sapagkat ang lingid na ideolohiya nito, na nakakubli sa realismong taglay ng verité, ay exposisyon lamang sa mahirap, ng pagiging mahirap, at pagpapakita ng kalagayan ng mga taong lugmok sa kahirapan. Ang sentral na diskurso nito ay nakatali sa sinasabi ni O'Shaughnessy (2007) na "miserabilism" (p. 29). Isang anyo ng paglalarawan sa kahirapan na nangangapital sa mga imaheng kalunos-lunos, nakakasulasok, at kaawaawa. Sa huli, wala itong tala ukol sa ugat ng inilalarawang kahirapan at lalong wala itong panawagan kung sa paanong paraan ba maaring makilahok ang manonood upang maging mga kabahagi sa pagbabago ng panlipunang kondisyon na ito. At sa ganitong arelo ng pag-iisip tayo nais salamangkahin ng naturang miserableng dokumentaryo. 
Nabubuhay tayo ngayon sa isang lipunang ang lahat ay pinapaslang. Pinapaslang ng walang pakundangan ang mga mahirap sa ngalan ng Oplan Tokhang. Kinikitil ang mga tumutuligsa sa pamahalaan. Sinasagkaan ang kalayaang makapagsalita. Binabantaan ang mga paaralan at mga guro nito na iwasang maging kritikal sa pamahalaan. Binubusalan ang landas tungo sa tunay na kaunlaran. Higit sa lahat pinapaslang ang kakanyahan nating mangarap ng mas makatwiran at makataong lipunan. At kung maging sa mga dokumentaryo ng kasalukuyan ay walang espasyo ang mga mahirap upang makapagsalita, hindi siguro kalabisang sabihin na batay sa kondisyon ng ating lipunan ngayon ay alam na natin kung kanino pumapabor ang ganitong mga mapagkunwang likha. Tiyak na hindi sa mga mahirap at sa sambayanang Filipino.

\section{Konklusyon: Ang Tunguhin ng Dokumentaryo sa Panahon ng Pasismo at Pagpaslang sa Politikal}

Nitong nakaraang 2019 UP Gawad Plaridel ng Kolehiyo ng Pangmdalang Komunikasyon ay si Bonifacio Ilagan ang napiling bigyan ng naturang pagkilala (UP Gawad Plaridel 2019 citation, 2019). Si Boni ay isang aktibistang tinortyur noong panahon ng diktadurang Marcos (Rodriguez, 2019). Siya ay manunulat sa telebisyon, teatro, radyo, at pelikula ng mga obrang naglalayong ibulgar ang mga kamalian sa lipunan at isulong ang isang lipunang makatao, makamamayan, malaya, at tunay na maunlad.

Ilang araw bago ang seremonya ay inedit ng ilang kinatawan ng sistema ng Unibersidad ng Pilipinas Diliman ang ingles na bersyon ng pagkilala. Kinaltas nito ang pariralang nagsasaad na siya ay tinortyur noong panahon ng Batas Militar. Ito'y sa kadahilinang wala naman daw itong koneksyon sa kanyang pagtanggap ng gawad at sa kanyang panulat. Kabaligtaran ng kanilang haka, ang lahat ng isinusulat ni Boni ay may kaugnayan sa kanyang danas bilang aktibista, bilang survivor ng Martial Law, bilang kapatid ng desparasido, at bilang tunay na rebolusyonaryo.

Hindi simpleng usapin ang pag-edit sa pagkilala. Bukod sa pag-umit ito sa katotohanan, garapalan itong pagpaslang sa larangan ng "politikal" mula sa mga arkitekto ng namamayaning kaayusan sa loob ng Pamantasan ng Bayan.

Ang pagpaslang na ito sa "politikal" sa loob mismo ng akademya ay mula sa mga sugo ng idea ng yugtong "post-poltikal". Kung saan ibinabandera sa mga moog ng pagkatuto ng mga apologist nito na "marapat lamang pipiin ang mga diskursong tumatalakay sa tunggalian ng mga uri, sosyalismo at komunismo" (Raymundo, 2006, p. 218). Ito'y sapagkat bukod sa wala na daw itong bisa, ang tanging wika na lamang daw na maaring pang hawakan ng mamamayan at estado ay ang adyendang hatid ng neoliberalismo. Sa 
loob ng akademya, mahihinuhang laging naka-amba at hindi natutulog ang mga nakaupo sa trono at alipores ng pasismo, pambansa estado, at reaksyunaryong politika.

At ngayong nabubuhay tayo sa lagim na hasik ng administrasyong Duterte, kailangang makita natin na malawakan at sistemiko ang kampanya nito upang kitilin ang larangan ng politikal. Malinaw itong mababatid sa kanyang mga polisiyang pang ekonomiya, sa represyon sa media, sa militarisasyon sa mga paaralan at kanayunan, sa pagpatay sa hanay ng mga puwersang nakikitunggali, sa pagyurak sa karapatang pantao, at higit sa lahat sa paglikha ng isang kahariang nais buhayin ang lahat batay sa pananakot. Ang "chilling effect" at pagpaslang sa politikal na hatid ng rehimen ni Duterte, at maging ng mga nauna sa kanya, ang mga usapin at katotohanang marapat nating magupo at maigpawan. Nang sa gayon ay maging mga kasanib tayo ng mga alternatibo at transpormatibong mga pagkilos at pakikitunggali na layong lansagin ang sistemang mapang-aping mata sa mata, pangil sa pangil.

Kung pinapaslang ang politikal at binubura sa gunam ng mamamayan ang nagpapatuloy pa ding tunggalian ng mga uri, saan nga ba dapat lumugar ang mga dokumentarista at dokumentaryo ng ating panahon sa digmaang ito? Kung ang sandigan ng anyong dokumentaryo ay ito ang medium na palagiang may taya sa katotohanan, anong anyo at uri ba ng realismo at katotohanan ang tinatayaan ng ilan sa mga dokumentarista ng kontemporaryong panahon?

Hindi pwedeng mabuhay sa gitna at mamagitna ang sinomang alagad ng sining at media. Sa panahon ngayon kung saan ang lahat ng maaaring galawan ay may nakaumang na banta, kailangang maging partisano ng dokumentarista sa talaban ng katotohanan at ng mga uri.

Ang prinsipyadong dokumentarista ay marapat na tumaya sa poltikal nang sa gayon ay maipakita, maipadinig, maipaunawa at maging kaisa ang dokumentarista sa laban ng mamamayan upang itaob ang nambubusabos, upang lansagin ang mga tanikala ng pagkaalipin, at upang maging kapwa mga mandirigma sa laban ng uring nilalapastangan.

Marapat ding tanungin ng mga dokumentarista ng kontemporaryong panahon at maging ng mga guro sa mga moog ng pagkatuto ukol sa disiplina ng pelikula at media kung gumagawa lamang ba sila ng mga dokumentaryo ukol sa kahirapan, problemang panlipunan, at mga naratibo ng nagdaan upang manalo ito ng mga gawad, upang maka-ikot sa mga festivals, upang purihin ng mga patimpalak ng unang daigdig, upang mag-ipon ng mga parangal, upang maging bahagi ng canon ng pelikula, upang muling makakuha ng pondo para makagawa ulit ng sablay na pelikula, at upang 
kilalanin bilang dokumentarista ng bayan ng mga institusyon, ng mga daluyan ng kapital, at maging ng estado.

Kung gayon ang baluktot at anti-mamamayang asta at dahilan kung bakit gumagawa ng mga dokumentaryo ang mga nasa mundo ng sining at mga nagsipagtapos ng kurso sa media, na paratihang ginagawang sangkalan ang danas at buhay ng masang Filipino sa kanilang mga obra, natitiyak kong bahagi kayo ng patuloy na inhustisya at paghihirap ng ating bayan. Pakatandaan lamang na malupit maningil ang kasaysayan at sambayanan sa mga taong nagtaksil sa mamamayan.

Wala ng ibang panahon upang mamili ng panig. Sapagkat ang digmaan para sa bayan ay matagal ng nagsimula at nagpapatuloy. Sa tindi ng kadilimang nagaganap sa lipunan, ang panig at pakikiisa lamang sa masa ang pinaka makatwiran at makataong pasya.

At kung gagamitin nating sandata ang larangan ng dokumentaryo at hihigitin ang radikal na potensyal nito, natitiyak kong tunay na sine para sa bayan ang inyong malilikha at ang sambayanang lumalaban ang kikilala sa inyo sa daigdig ng mga sakahan, pabrika, lansangan, digmaan, at kamalayan-hanggang sa tagumpay ng hindi pa natatapos na rebolusyon ng sambayanan! 


\section{Sanggunian}

Arumpac, A.(2019).Digital documentary traditions. Nasa Art archive 02: A collection of essays on Philippine contemporary literature and film. Japan Foundation, Philippines.

Asia Maritime Transparency Initiative.(2019).Failin or incomplete? Grading the South China Sea arbitration. Retrieved from https://amti.csis.org/failing-or-incomplete-grading-the-south-chinasea-arbitration/.

Badiou, A.(2013).Cinema. UK: Polity Press.

Bato, J.(2019).Shoot the revolution: People's cinema and political film collectives in the Duterte era. Unpublished undergraduate thesis, University of the Philippines College of Mass Communication, Quezon City.

Dalena, K.(Producer \& Director).(2004).Red saga.[Motion Picture]. Philippines: Mowelfund Institute.

Sicat, K.(Producer), \& Dalena, K. \& Dalena, S.(Directors).(2013). The guerilla is a poet.[Motion Picture]. Philippines: Kino Arts.

Dutta, M.(2011).Communicating social change. UK: Routledge.

Educators Forum for Development. (2020). Anti-terrorism bill silences dissent, curtails democratic rights. IBON. Retrieved from https://www.ibon.org/anti-terrorism-bill-silences-dissent-curtailsdemocratic-rights/

Esmaquel II, P. (2016). Ombudsman hits revision of history amidst marcos burial protests. Bulatlat. Retrieved from https://www.rappler.com/nation/153697-ombudsman-morales-revision-historymarcos-burial

Espada, D.(2004).Rustic fields and peasant flags in Red Saga. Bulatlat. Retrieved from https://www. bulatlat.com/news/4-24/4-24-saga.html.

Guillermo, A.(2001).Protest/Revolutionary art in the Philippines 1970-1990. Quezon City: UP Press.

Human Rights Watch.(2019).Philippines events of 2018. Retrieved from https://www.hrw.org/worldreport/2019/country-chapters/philippines.

IBON Media \& Communications. (2016). Path not to take: The exclusionary and elitist daang matuwid. Retrieved from https://www.ibon.org/path-not-to-take-the-exclusionary-and-elitist-daangmatuwid/

Imbong, R. (2020). On the question of fascism in relation to the duterte regime: Interview with jose maria sison. National Democratic Front of the Philippines. Retrieved from https://ndfp.org/on-thequestion-of-fascism-in-relation-to-the-duterte-regime/

Iglesias, R. (1984, December 16). An emerging people's cinema. Sunday Malaya. P.7.

Karapatan.(2019).2018 Karapatan year-end report on the human rights situation in the Philippines. Retrieved from https://www.karapatan.org/2018-Karapatan-HR-Report.

Lee, Y. (2020).Conviction of Philippine journalist points to 'orchestrated' attempt to silence duterte critics. CNBC. Retrieved from https://www.cnbc.com/2020/06/16/maria-ressas-conviction-attempts-tosilence-duterte-critics-expert-says.html

Manzanillia, J. (2006). Terror talks: The public secret. In R.B. Tolentino \& S. Raymundo(Eds.), Kontra-Gahum: Academics against political killings (pp.96-105). Quezon City: Ibon Books.

Maranan,J.(Producer \& Director).(2011).Tundong magiliw.[Motion Picture]. Philippines: Goethe-Institute Manila et. al.

Nichols, B.(2001).Introduction to documentary. USA: Indiana University Press.

Olea, R. at Cataneda, D. (2004). The hacienda luisita massacre: How it all happened. Bulatlat. Retrieved from https://www.bulatlat.com/2004/11/28/the-hacienda-luisita-massacre-how-it-happened/

O'Shaughnessy, M.(2007).The new face of political cinema. New York: Berghahn Books.

Pangilinan, C. (2012).Mula wowowee hanggang ultra:Telebisyon, uri at idelohiya. In Philippine Humanities Review (14), 2, 43-81.

Philippine Statistics Authority.(2018).Nine Percent of Filipinos Aged 6 to 24 years are Out of School (Results from the 2017 Annual Poverty Indicators Survey).Retrieved from https://psa.gov.ph/ content/nine-percent-filipinos-aged-6-24-years-are-out-school-results-2017-annual-povertyindicators.

Rabinowitz, P.(1994).They must be represented: The politics of documentary. London: Verso.

Raymundo, S.(2006).Ang etika ng tunay laban sa diskurso ng wakasan. In R.B. Tolentino \& S. Raymundo(Eds.), Kontra-Gahum:Academics against political killings (pp.203-230). Quezon City: Ibon Books. 
Raymundo, S. (2015).Trahedyang wowowee: Hindi lintik mula sa langit. In R.B. Tolentino \&G. Devilles (Eds.), Kritikal na espasyo ng kulturang popular (pp.31-44). Quezon City: Ateneo de Manila Press.

Rodriguez, R. (2019). Simulain ng iskolar ng bayan. In U.P. Gawad Plaridel 2019, UP College of Mass Communication-Diliman, Quezon City.

Rodriuez, R. \& Pangilinan, C. (2019). Sa madaling salita: Kasaysayan at pag-unlad ng Wikang Pambansa. Quezon City: Sentro $\mathrm{n}$ Wikang Filipino-UP Diliman.

Roque, R.( (2018). Artsibo at sineng bayan: Pagpapanatili ng kolektibong alaala at patuloy na kolektibong pagsalungat sa kasinungalingan at panunupil. In Plaridel (15), 2, 71-112.

San Juan, E.(2006).Neocolonial state terrorism and the crisis of comprador/imperialist hegemony. In R.B. Tolentino \& S. Raymundo(Eds.), Kontra-Gahum: Academics Against Political Killings (3-26). Quezon City: Ibon Books.

Solanas, F.\& Gettino, O. (1976).Towards a third cinema.In B. Nichols (Ed.),Movies and methods (Volume I, pp.44-64).Berkeley: University of California Press.

Enouye, K.(Producer), \& Tagaro, V. \& Uriu, T.(Directors).(2018).Yield [Motion Picture]. Philippines: T.I.U. Films.

Tolentino, R.(2016).Indie cinema at mga sanaysay sa topograpiya ng pelikula ng Filipinas. Manila: UST Press. Tudla Productions (Producer \& Director).(2005). Sa ngalan ng tubo. [Motion Picture]. Philippines: Tudla.

Umil, A. (2011). Oplan bayanihan blamed for continuing rights violations. Bulatlat. Retrieved from https://www.bulatlat.com/2011/12/11/oplan-bayanihan-blamed-for-continuing-rights-violations/

U.P. Gawad Plaridel Citation (2019). UP College of Mass Communication-Diliman, Quezon City.

Winston, B.(1995).Claiming the real: The Documentary film revisited. London: Routledge.

CARLO GABRIEL "CHOY" S. PANGILINAN is Senior Lecturer 2 at the UP Film Insititue, College of Mass Communication, University of the Philippines (UP) Diliman. He is co- editor of the books Communication and Media Theories (UP Press, 2014), Sa Madaling Salita: Kasaysayan at Pag-unlad ng Wikang Pambansa (SWF-UP Diliman, 2019 and editor of Tanbata's Wife: From Text to Screen (UP ICW, 2019). He is also a member of the film collective Sine Sanayata. (corresponding author: kontradiskurso@gmail.com) 
